\title{
Vài dòng tản mạn về JSTOR, xưa và nay
}

\author{
Vương Quân Hoàng \\ AISDL, Vuong \& Associates
}

Hà Nội, 29-8-2020

Tình cờ có việc tìm kiếm JSTOR, chợt nhớ lại một vài quan sát từ rất lâu về hệ thống quan trọng với công việc tra cứu tài liệu học thuật này, từ trước thiên niên kỷ mới.

\section{Chuyện đã lâu...}

Cách đây hơn 20 năm, tôi có dịp lần đầu tải các bài nghiên cứu về từ JSTOR. Nguyên do cũng rất tình cờ. Lúc đó cần đọc một số tài liệu kỹ thuật và thị trường về ngành dệt may, thì mới log-on vào hệ thống MIS của The World Bank.

Không khó để nhận ra, khi đó WB cung cấp nhiều tài liệu phục vụ việc tra cứu trích xuất từ CSDL của JSTOR. Hệ thống này có một logo đặc trưng, đẹp và ấn tượng khó quên.

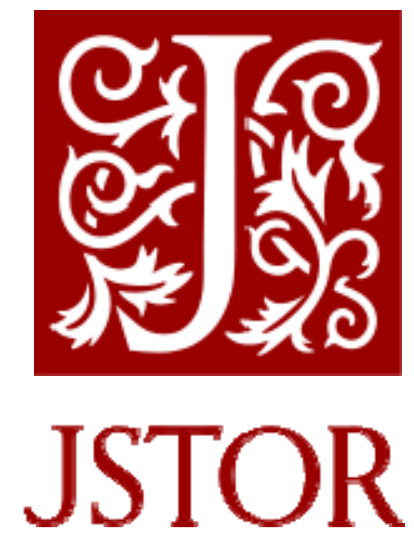

Biểu tượng của JSTOR, lấy từ Wikipedia: https://en.wikipedia.org/wiki/JSTOR

Về công dụng thì có lẽ không cần nói nhiều. Thời kỳ thiếu thốn thông tin, dữ liệu, và đường truyền khó khăn những năm 1997-98 mà có được kho tư liệu này (thời kỳ chưa có Google Scholar và các Preprints Servers) thì tự đó cũng đã nói lên mọi thứ.

Lúc đó có một cản trở. Đôi khi cảm thấy rất bứt rứt, vì có các tài liệu mới biết rõ là tồn tại, nhưng JSTOR không cho đọc. Đó chính là vì quy tắc "5-year moving wall". Đến bây giờ, quy tắc này vẫn duy trì.

Nói chung, với đầu óc và hiểu biết rất hạn chế, tôi vẫn có vài quan sát thô sơ như sau: 
a) Các ấn phẩm ở trong JSTOR đều của các nhà xuất bản quen thuộc, có tiếng tăm, và dễ tạo niềm tin. Phần lớn là University of Chicago Press, Pegasus, North-Holland, Wiley, Blackwell, v.v..

b) Các bài báo trong các ấn phẩm được "số hóa" cẩn thận trước khi đưa lên. Các bài báo cũ đều được quét (scanned) thành các tệp pdf có độ nét đủ tốt để đọc (có lẽ là tốt nhất với công nghệ thời kỳ đó). Tôi còn nhớ, JSTOR cho tải về 2 loại tệp pdf với cùng một bài: loại chất lượng in tốt (tệp lớn, nặng trịch, mỗi bài báo nhiều $\mathrm{MB}$ ), và loại chất lượng in vừa phải gọi là fax-machine quality, nếu nhớ không nhầm (tệp nhẹ hơn nhiều, phổ biến là vài trăm KB tùy theo độ dài và số lượng hình ảnh).

c) JSTOR cũng xây dựng hình ảnh rất cẩn thận. Mỗi bài được gắn thêm một trang đầu tóm tắt metadata của bài và có logo JSTOR. (Vào thời điểm đó thì cũng hiểu là họ chuẩn hóa thông tin, nhưng sau này khi tham gia công tác biên tập với tạp chí Scientific Data, tôi mới hiểu sâu hơn giá trị của các thông tin này.)

Nói cho đúng thì JSTOR là cơ sở dữ liệu học thuật đầu tiên mà tôi có quyền truy cập, và say mê tìm đọc tài liệu trong nhiều đêm dài. Nó có tác dụng mở mắt để nhìn thấy công tác tổ chức dữ liệu tuyệt vời thế nào (kể cả có rất nhiều hạn chế, nếu so với các hệ thống cực mạnh ngày nay).

\section{Đầu thập niên 2000s}

Trong khi vẫn còn truy cập được vào JSTOR, tới đầu những năm 2000s, tôi nhận thấy có một hệ thống dữ liệu nữa được bổ sung: Sciencedirect của Elsevier. Ngày nay thì hệ thống này đã quá mạnh rồi, nhưng khi đó thì chỉ những người làm việc liên quan mới quen thuộc: https://www.sciencedirect.com.

Cũng không khó để nhận thấy là rất nhiều tài liệu có trên JSTOR không hề có trên ScienceDirect, và ngược lại. Một khác biệt nữa có thể nhận thấy, là ScienceDirect có các bản "pdf downloadable" dường như được chế bản nhẹ, đẹp và nét (chất lượng in tốt hơn hẳn) so với JSTOR. Lúc đó, tôi chỉ nghĩ các hệ thống khác nhau, thì có nền tảng kỹ thuật khác nhau, không nghĩ tới thực tế là các hãng cũng cạnh tranh nhau quyết liệt về sản phẩm. Và chế bản khoa học, xét cho đến cùng cũng là một loại sản phẩm và công nghệ tốt, tiện dụng, chất lượng cao chính là vũ khí cạnh tranh lợi hại.

Những cái khác biệt tưởng chừng nho nhỏ về trải nghiệm của người dùng như thế có lẽ chính là nguồn cơn những cuộc cạnh tranh khốc liệt của các ông lớn hôm nay, và dáng vẻ của nó đã có thể thấy trong cuộc thư hùng đương đại giữa Web of Science (bao gồm cả ISI, nay thuộc về tay Clarivate Analytics sau nhiều năm dưới sự quản lý của Thomson Reuters) và Scopus (chính là sản phẩm hệ thống bibliographic của ông lớn Elsevier).

\section{Thời kỳ bùng nổ công nghệ và ứng dụng thông tin}


Bây giờ đã là 2020, bắt đầu thập niên thứ 3 của thế kỷ XX. Cuộc bùng nổ công nghệ số, công nghệ thông minh và cách mạng dữ liệu đã phả hơi nóng vào mọi ngóc ngách của thế giới.

Ngày nay thì học sinh ở Việt Nam cũng thuần thục việc sử dụng Google và Google Scholar để tìm kiếm các tài liệu cho học tập, đề án, v.v.. Cũng không còn thấy ai nhắc đến JSTOR. Lâu ngày không dùng, và không nghe nhắc đến, bản thân tôi cũng quên mất đó đã từng là cửa ngõ đầu tiên dẫn mình vào địa hạt thông tin khoa học có tính hệ thống, và mênh mông bao la, chỉ từ bàn phím máy PC. JSTOR dường như không còn tồn tại nữa, cho tới ngày...

Một ngày xuân 2019, lúc ấy xong một bản thảo nghiên cứu, sau này là bài xuất bản [1], tôi phải quyết định việc lựa chọn nơi nộp bài. Lựa chọn là tạp chí của Brill, European Journal of East Asian Studies (ISSN: 1570-0615). Brill là nhà xuất bản lâu đời bậc nhất thế giới, từ năm 1683! (Năm nay "cụ" Brill đã 337 tuổi Trời rồi đấy.)

Tuy vậy, khi thấy tạp chí tốt và phù hợp, tôi hơi phân vân vì dù trong Scopus nhưng tạp chí lại chưa chỉ mục hóa trong Web of Science (hiện đang là trào lưu). Nên tìm thêm thông tin, thì thấy xuất hiện logo JSTOR. Cảm thấy như gặp lại bạn cũ.

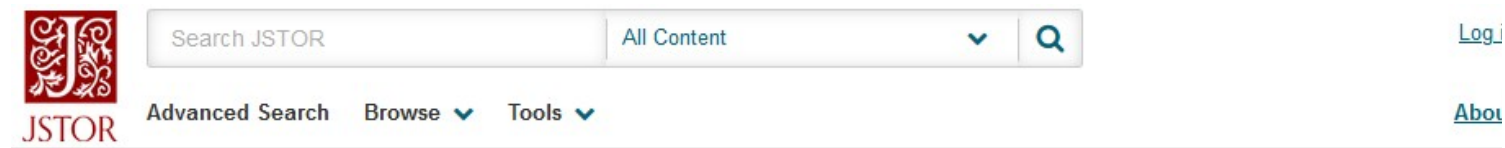

\section{European Journal of East Asian Studies}

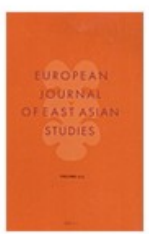

Coverage: 2001-2016 (Vol. 1, No. 1 - Vol. 15, No.

Published by: Brill

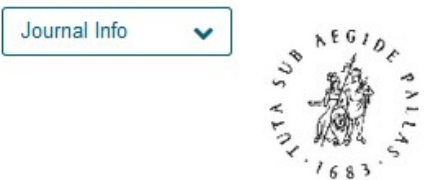

B R I L L

All Issues

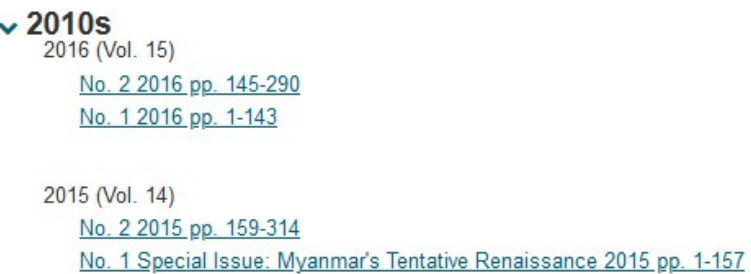

2014 (Vol. 13)

No. 2 Special Issue: The Great Spoliation: The Socialist Transformation of Industry in 1950s China

https://www.jstor.org/journal/eurojeastasiastu 
À, và đúng là người bạn ấy. Vẫn cái "moving wall” 5 năm. Như trong hình trên từ JSTOR, nội dung gần nhất được truy cập là khoảng đầu 2016, vì người dùng chỉ được sử dụng các thông tin cơ bản đã 5 năm tuổi.

Như vậy, theo quy tắc này thì bài xuất bản năm 2019, phải tới 2024, mới được đưa vào CSDL mà người dùng JSTOR có thể truy cập. Đây là thiệt hại lớn, vì với các Preprints Servers/Repositories đang ngày càng mạnh như Academia.edu, ResearchGate, OSF, Philpapers, etc. thì chắc chắn sẽ không có độc giả nào chịu chờ 5 năm đâu! (Đó là chưa nói tới việc tìm kiếm hết sức dễ dàng qua trang web lừng danh Sci-Hub.)

Cũng theo quy tắc 5-năm, thì một bài khác (thể loại book review) xuất bản năm 2014 trên Pacific Affairs (ISSN: 1715-3379) thì có sẵn và có thể truy cập/tải về từ JSTOR [2] ${ }^{1}$

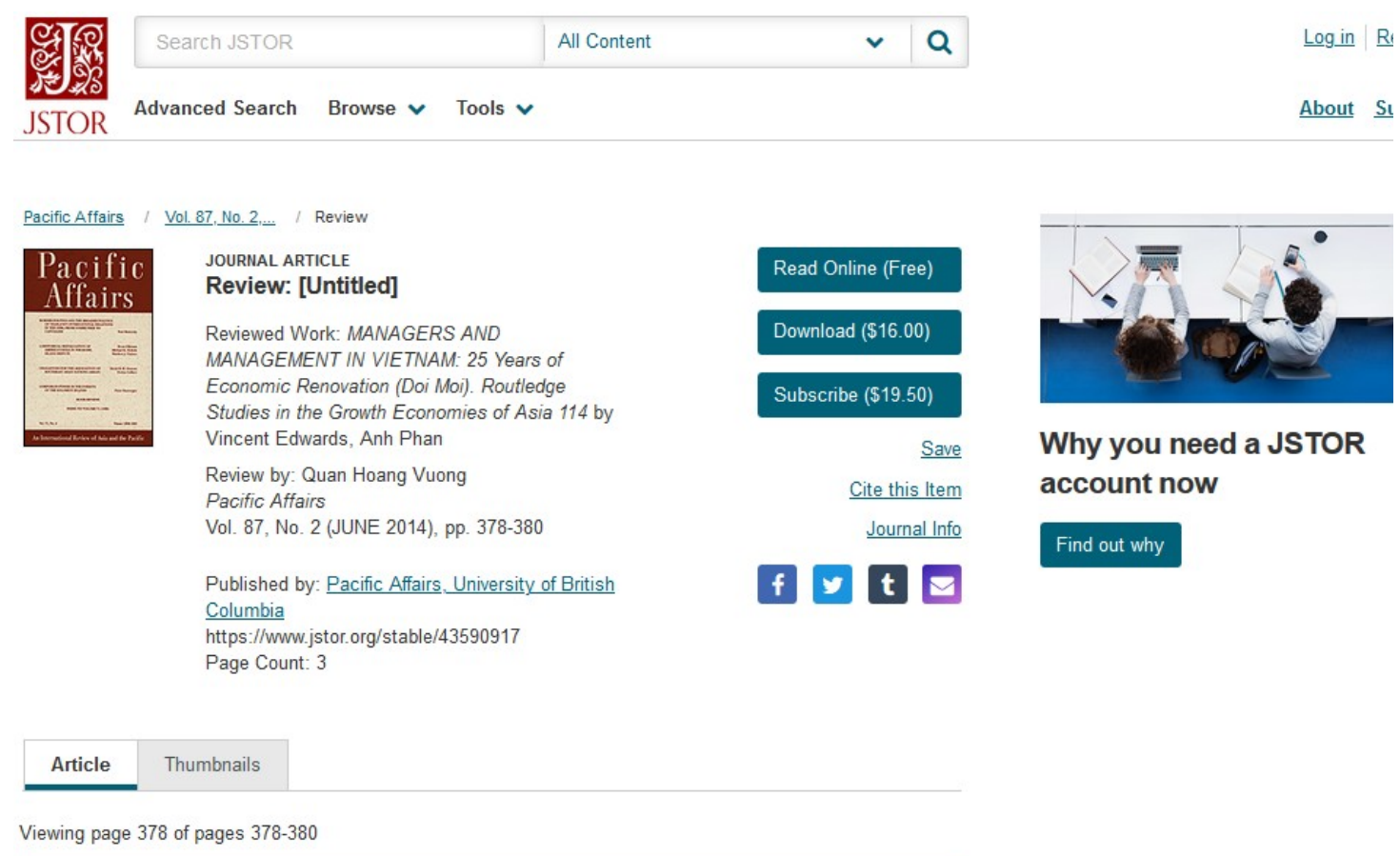

PREVIEW

https://www.jstor.org/stable/43590917?seq=1

Hiện tại, hệ thống JSTOR đã có một giao diện web rất thân thiện. Họ cũng đã tăng cường các mục thông tin bài vở phổ thông, có tính cách phổ biến cập nhật thông tin khoa học. Nhiều thông tin khai thác từ lịch sử dữ liệu hàn lâm cũng rất lý thú, nhờ vào hệ thống lớn tích lũy lâu ngày của 2600 tạp chí hàn lâm hàng đầu, từ 1200 nhà xuất bản của 57 quốc gia. Hàng ngày, có

\footnotetext{
${ }^{1}$ Đây là tạp chí rất lâu đời do University of British Columbia xuất bản từ năm 1928; có địa chỉ truy cập Internet tại: https://pacificaffairs.ubc.ca.
} 
nhiều thông tin hay như bài mới ra ngày 19-8-2020 có tựa đề "Plague and Protest Go Hand in Hand" [3] có thể đọc miễn phí từ địa chỉ: https://daily.jstor.org.

Trông vậy mà để tóm tắt lại chuyện be bé này cũng phải tốn khá thời gian trải nghiệm. Thôi thì bỏ chút công, nay ghi lại như một dấu mốc thời gian.

\section{Tài liệu tham khảo:}

[1] Vuong, Q. H., Vuong, T. T., Ho, M. T., \& Nguyen, H.-K. T. (2019). The 'same bed, different dreams' of Vietnam and China: how (mis)trust could make or break it. European Journal of East Asian Studies, 18(1), 93-128.

[2] Vuong, Q. H. (2014). Managers and Management in Vietnam: 25 Years of Economic Renovation. Pacific Affairs, 87(2), 378-389.

[3] Atwood, E. K., \& Williamson, S. (2020, Aug. 19). Plague and protest go hand in hand. JSTOR Daily. URL: https://daily.jstor.org/plague-and-protest-go-hand-in-hand. 